\title{
Sürdürülebilir Kalkınma Hedefleri Çerçevesinde Kültür ve Turizm Bakanlığı'na Bağı Halk Kütüphanelerinin Faaliyetlerinin Değerlendirilmesi
}

\author{
Assessment of the Activities of Public Libraries Affiliated to the Ministry of Culture \\ and Tourism within the Framework of Sustainable Development Goals
}

\author{
Nuh Mehmet Topkaraoğlu*
}

$\ddot{O} z$

Sürdürülebilir Kalkınma Hedefleri, Birleşmiş Milletler (BM)'in yoksulluğu yok etmek, barış ve refah içinde yaşamak ve gezegeni korumak için üye ülkelerin önüne koyduğu hedeflerdir. BM, bu hedefleri 2030 yllına kadar gerçekleştirmeyi planlamaktadır. Gerçekleşen kalkınmanın sürdürülebilir olması için kalkınmanın nüfusun her kesimine yayllması gerekmektedir. Bu noktada halkın her kademesine ücretsiz hizmet sunan kütüphaneler Sürdürülebilir Kalknnma Hedeflerinin doğal destekçisi olarak ön plana çılkmaktadır. Çalı̧̧mada kütüphanelerin bu varoluşsal rollerinin ortaya konması amaçlanmıştır. Kültür ve Turizm Bakanlığı kapsamında hizmet veren kütüphanelerin faaliyet raporları irdelenerek, Sürdürülebilir Kalknnma Hedeflerini destekler nitelikteki faaliyetler tespit edilmeye çalışılmıştır. 2006-2019 arası 14 faaliyet raporu değerlendirilmiştir. Araştırma göstermektedir ki kütüphanelerin verdiği eşitlikçi, demokratik ve kapsayıcı hizmetler, hali hazırda kalkinmayı tabandan desteklemektedir.

Anahtar Sözcükler: Sürdürülebilir kalkınma; halk kütüphaneleri; Birleşmiş Milletler.

\begin{abstract}
The Sustainable Development Goals are the goals set by the United Nations (UN) to eradicate poverty, to live in peace and prosperity, and to protect the planet. The UN plans to accomplish this initiative until the year 2030. In order for the development to be sustainable, it is expected to spread to all parts of the population. At this point, libraries that provide free services to all levels of the community come to the forefront as the natural supporter of the Sustainable Development Goals. In this study, it is aimed to reveal these existential roles of libraries. Therefore, the activities supporting the Sustainable Development Goals were tried to be determined by examining the activity reports of the libraries serving within the body of the Ministry of Culture. For this purpose, fourteen (14) activity reports between the years of 2006 and 2019 were evaluated. Research shows that the equitable, democratic and inclusive services provided by libraries already support development.
\end{abstract}

Keywords: Sustainable development; public libraries; United Nations.

\footnotetext{
*Öğr. Gör., Tarsus Üniversitesi, T1bbi Dokümantasyon ve Sekreterlik Programı. E-posta: nuhtopkaraoglu@tarsus.edu.tr

Lecturer, Tarsus Universiy, Medical Documentation and Secretarial Program.
}

Geliş Tarihi - Received: 06.12 .2020

Kabul Tarihi - Accepted: 13.03.2021 
Sürdürülebilir Kalkınma Hedefleri Çerçevesinde Kültür ve Turizm Bakanlığı'na Bağlı Halk Kütüphanelerinin Faaliyetlerinin Değerlendirilmesi

Assessment of the Activities of Public Libraries Affiliated to the Ministry of Culture and Tourism within the Framework of Sustainable Development Goals

\section{Giriş}

İnsan, tarih boyunca doğanın bir parçası olarak hayatta kalmıştır. Başlarda avcı-toplayıcı olan insan türü sonraları yerleşik hayata geçerek ilk üretimi gerçekleştirmiştir. Üretim ile birlikte refahı da artan insanoğlu daha fazla tüketmeye başlamıştır. Bulunduğu çevre ihtiyaçlarına cevap verdiği sürece yerel kaynaklardan faydalanmış, ihtiyaçları (nüfusa ve yaşam tarzına bağlı olarak) arttıkça farklı bölgelerdeki kaynaklara yönelmiştir. Özellikle sanayi devrimi sonrası bireysel üretimden makine üretimine geçen insanlık, çevresel kaynakları daha hızlı tüketir hale gelmiştir. Bu da yeni kaynaklara olan ihtiyacı artırmış ve buna paralel olarak doğadaki tahribat da artmıştır. Günümüzde de devam eden yıkım süreci, sınırlı olan doğal kaynakları tüketmektedir. Doğal kaynaklar üzerinden yaşanan yok edişin aslında yok oluş anlamına geldiğini geride kalan yüzyılda anlamaya başlayan insanoğlu, artmakta olan çevresel tehditler ve tükenmeye başlayan doğal kaynaklar ile yüz yüze kalmıştır. Tüketime dayalı bu sistemin yaşanabilir bir dünya bırakmayacağı düşünüldügünde, insanlar önce yenilenebilir kaynaklara yönelmiş, sonrasında ise sürdürülebilir tüketime çare aramaya başlamıştır.

Sürdürülebilirliğin birçok tanımı olsa da temelde son yıllarda bu tema "gelecekten çalmama" üzerine inşa olmuştur. Önceleri sadece devamlılığı sağlama anlamına gelen sürdürülebilirlik, günümüzde kaynakları koruma ve gelecek nesillere aktarma şeklinde tanımlanmaktadır. Kaliforniya Üniversitesi bunu sürdürülebilir kalkınma altında işleyerek "Gelecek nesillerin kendi ihtiyaçlarını karşılama yeteneğinden ödün vermeden günümüzün ihtiyaçlarını karşılayan kalkınma" şeklinde tanımlamaktadır (California University, 2020). Başka bir çalışmada ise sürdürülebilir kalkınma dünyanın devamlılığını koruma altına almak için ekolojik ve bilimsel anlayışın bir arada yürütülmesi gerektiğine vurgu yapılmaktadır (Kılıç, 2013, s. 205). Sürdürülebilir kalkınma, Birleşmiş Milletler (BM) tarafından ilk defa 2005 yılı genel kurulunda tanımlanmıştır. BM, sürdürülebilir kalkınma çerçevesinde 3 ana başlığa odaklanmaktadır. Bunlar ekonomik sürdürülebilirlik, çevresel sürdürülebilirlik ve sosyal sürdürülebilirliktir. Sürdürülebilir Kalkınma Hedefleri, BM tarafından yoksulluğu ortadan kaldırmak, gezegeni korumak, barış ve refah içinde yaşamak için ülkelerin önüne konulmuş olan hedeflerdir. 2030 yılına kadar bu hedefleri gerçekleştirerek dünyayı herkes için yaşanabilir bir yer haline getirmeyi amaçlayan BM, bu kapsamda yer alan çalışmalar yürüten hükümetlere de destek olmaktadır (Birleşmiş Milletler, 2020). BM bu amaçları belirlerken, kalkınmanın sürdürülebilir olması için toplumun her kesiminin kalkınmanın içinde yer alması gerektiğini göz önünde tutmuştur. Bu sebeple de kapsayıcı olmaya çalışarak hem hedef kitleyi bütün insanlar olarak belirlemiş, hem de bütün insanların ortak sorunlarını çözmeyi temel alan bir yaklaşım sergilemiştir.

Sürdürülebilir kalkınmanın en önemli destekçilerinden birisi de sorumlulukları gereği şüphesiz kütüphanelerdir. Bilgi olmadan kalkınmanın olması düşünülemez. BM'nin koyduğu hedefler doğrultusunda kütüphaneler kalkınmaya ilişkin bu görevleri başarmada önemli roller üstlenmelidirler ki, IFLA tarafından öngörülende budur. Ülkemizdeki kütüphanelerin yaptıkları icraatlar bu yaklaşımla daha önce araştırılmamıştır. Özellikle halk kütüphanelerinin toplum temelli bir kalkınmada kilit önem taşıdıklarını söylemek yanlış olmaz. Bu önemli kurumların sürdürülebilir kalkınmadaki rollerini daha iyi tanımlamak adına, faaliyetlerini yakından incelemek gerekir. Bu çalışmanın amacı bu faaliyetleri irdeleyerek Kültür ve Turizm Bakanlığı 
bünyesindeki bu kuruluşlarda yürütülen Sürdürülebilir Kalkınma Hedeflerine yönelik (bu amaçla yapılmasa bile) icraatları tespit etmektir. Aynı zamanda ileride halk kütüphanelerine bu bağlamda verilecek görevlere bir dayanak noktası oluşturmak çalışmanın hedefleri arasındadır.

\section{Literatür}

Sürdürülebilir kalkınma konusu literatürde geniş olarak işlenmektedir. Kalkınma ve kütüphaneler konusu ise çok araştırılan bir konu olmamıştır. Kütüphanelerin kalkınma programlarındaki yeri 1970'li, 80'li ve 90'lı yıllarda ele alınmış, ancak BM kalkınma amaçları çerçevesinde kütüphanelerin rolü fazla işlenmemiştir. Buradan hareketle, literatürde yer alan çalışmalar belirlenirken kalkınma ve eğitim alanında toplumun gelişimini anlatan çalışmalara yer verilmeye çalışılmıştır.

1975 yılında yapılan bir çalışmada, kütüphane ve bilgi hizmetlerinin ulusal düzeyde planlanması işlenmektedir. Araştırmacı, ulusal kalkınmanın olabilmesi için ulusal anlamda nitelikli bilgi sağlama hizmeti ve kütüphanelere ihtiyaç olduğu konusuna çalışmasında değinmiştir (Mohrhardt, 1975, s. 63). Bu konu, amacı üye ülkeleri eğitim, bilim ve kültür alanlarında geliştirmek olan UNESCO'nun çalışmalarında da geçmektedir. UNESCO ülkelerin eğitim, kültür ve bilim alanlarında gelişmesi için herkesin eşit haklara sahip olmasını, temel özgürlükleri, saygıyı, ırkçılık karşıtlı̆̆ını savunarak evrensel barışı tesis etmeye çalışmaktadır. 1945 yılında kurulan UNESCO tarafindan derlenen ilk raporda, bu hedeflere giden yolda kütüphanelerin önemine atıfta bulunulmaktadır (Parker, 1985,ss. 98-99). UNESCO’ya göre global iyileşmenin yolu kütüphanelerden geçmektedir. Çünkü kültürün temelini bilgi oluşturmaktadır. Bilginin kaynağı ise kuşkusuz kütüphanelerdir. UNESCO kütüphaneciliği destekleyici birçok faaliyette bulunarak eğitimin, bilimin ve kültürün gelişmesine katk1 sunmuştur.

UNESCO'nun Türkiye'de yürüttüğü çalışmalara Çapar'ın araştırmasında rastlamaktayız. Çapar özetle: ODTÜ Kütüphanesi, Hacettepe Üniversitesi Kütüphanesi, Devlet Arşivleri, TÜRDOK (Türkiye Bilimsel ve Teknik Dokümantasyon Merkezi), İstanbul Üniversitesi Kütüphanesi gibi birçok kurum yeni teknoloji (kitap patolojisi ve mikrofilm laboratuarı gibi) ile donatılmış ve konunun uzmanları söz konusu bilgi merkezlerine gelerek eğitim vermiş olsa da kütüphanelerin ülke genelinde desteklenmesi tam anlamı ile gerçekleştirilememiştir (Çapar, 1987, s. 174) demektedir. UNESCO Türkiye Milli Komisyonu ise sadece tabana kütüphane hizmeti yayılması ile yetinilmemesi ve etkili bir hizmet sunumu için öncelikle şehirlerin imar planlarında kütüphanelere yer verilmesi gerektiğini ifade etmiş ve kültürel gelişim için kütüphanelere "müzik bölümleri” kurulmasını önermiştir(UNESCO Türkiye Millî Komisyonu, 1974, s. 77). Günümüzde bu ilerici düşüncelerin Türkiye'de hayata geçemediğini görmekteyiz.

Kalkınma planlarında da kütüphaneler konusuna önem atfedilmektedir. Kalkınmada kütüphanelerin rolü olması gerektiği farklı planlarda dile getirilmiştir. Birinci Beş Yıllık Kalkınma Planında (1963-1967) kütüphaneye eğitim alanında yer verilirken, sonraki kalkınma planlarında kütüphane kültür başlığı altında değerlendirilmiştir. İlk Beş Yıllık Kalkınma Planında köylerde kitaplıklar kurularak eğitimin desteklenmesi gerektiği, İkinci Beş Yıllık Kalkınma Planında (1968-1972) ise kütüphanelerin yaygın eğitimi desteklemesi gerektiği belirtilmektedir. Bunun için halk eğitim merkezleri ile koordineli çalışarak, halkın eğitim 
Sürdürülebilir Kalkınma Hedefleri Çerçevesinde Kültür ve Turizm Bakanlığı'na Bağlı Halk Kütüphanelerinin Faaliyetlerinin Değerlendirilmesi

Assessment of the Activities of Public Libraries Affiliated to the Ministry of Culture and Tourism within the Framework of Sustainable Development Goals

seviyesinin yükselmesine yardımcı olunması gerektiği vurgulanmaktadır. Üçüncü (1973-1977) ve Dördüncü (1979-1983) Beş Yıllık Kalkınma Planlarında ise bina ve hizmet yeterlilikleri ve halka daha eşit imkânlar sunma adına her bölgeye gezici kütüphane temini ele alınmaktadır (Özdemirci, 1987, s. 199). Sekizinci Beş Yıllık Kalkınma Planına gelindiğinde dahi (20012005) hala kütüphanelerin yaygınlaştırılması gerekliliğine vurgu yapılmamaktadır (Holt, 2003, s. 81).

Kalkınma planlarında kütüphanelerin yer alması gerekliliği IFLA tarafından da önerilmektedir. IFLA tarafından BM'nin 2030 gündemine yönelik hazırladığı çalışmada, bilgiye erişimin bütün kalkınma hedefleri için gerekli olduğu belirtilmektedir. Kütüphanelerin dâhil edilmediği bir kalkınma planının eksik olacağına vurgu yapılan çalışmada, kütüphanelerin bu yöndeki fon ihtiyaçlarına değinmektedir. Sürdürülebilir Kalkınma Hedeflerine yönelik olarak da her ülkenin ihtiyaçları ve imkânları ölçüsünde farklı yollar benimseyebileceği öngörülmektedir (IFLA, 2016, s. 324). Raporda kütüphanelerin bu süreçte kendilerine nasıl yer bulmaları gerektiği ile ilgili öneriler, süreci yönetmeleri için gerekli bilgiler de yer almaktadır. IFLA bu çalışmada kütüphanelerin hangi yönleri ile kalkınma hedeflerine destek olacağını da şu şekilde listelemiştir;

- Medya ve bilgi okuryazarlığı da olmak üzere evrensel okuryazarlığ 1 ve dijital becerileri destekleyerek,

- Bilgiye erişim anlamındaki uçurumları kapatarak hükümetlerin, sivil toplumun, iş dünyasının ve halkın yerel bilgi ihtiyaçlarını daha iyi anlamalarına yardımcı olarak,

- Hükümet programları ve hizmetleri için bir hizmet noktası ağı sunarak,

- BİT erişimi yoluyla, kendilerini insanların yeni dijital beceriler geliştirmesine yardımcı olmaya adamış çalışanlarıyla dijital dünyaya dâhil olmayı geliştirerek,

- Araştırmacı ve akademik camianın kalbi olma görevini yürüterek,

- Dünya kültürünü ve mirasını muhafaza ederek ve bunlara erişim sağlayarak (IFLA, 2016, s. 332).

Konuyu bilgi toplumu stratejilerimiz ekseninde ele alan bir araştırmada da, kütüphaneler toplumun her kesimini eğitmenin aracı olarak sunulmaktadır. İlgili çalışmada bilgi teknolojilerinin yaygınlaştırılması, bilgi okuryazarlığı, görsel okuryazarlık, medya okuryazarlığı, bilgisayar okuryazarlığı eğitimleri verilmesi, bilgiye erişimde engellerin kaldırılarak engelli yurttaşlara gereken hizmetin sunulması ve bu sayede dezavantajlı bu kesimi sosyal hayata katabilme gibi birçok yönüyle kütüphanenin toplumun gelişimi ve bütünleşmesindeki rolüne değinilmiştir (Karadeniz ve Y1lmaz, 2016, s. 78).

Kuzey Amerika'nın halk kütüphaneleri düzeyinde öncü kuruluşlarından olan Kent Kütüphaneleri Konseyi, 2011 yılında sürdürülebilirlik ve sürdürülebilir toplum üzerine bir rapor hazırlanmıştır. Raporda sürdürülebilirliğin üçayağı olan ekonomik sürdürülebilirlik, çevresel sürdürülebilirlik ve sosyal sürdürülebilirliğe halk kütüphanelerinin katkıları değerlendirilmektedir. Rapora göre halk kütüphaneleri; yaşam boyu öğrenmeyi destekleyerek, bireye beceri kazandırarak, bireyin iş bulmasına ve kendini geliştirmesine destek sunarak ekonomik sürdürülebilirliğe katkı sunar. Yeşil binalar ve yeşil uygulamalar ile toplumda 
çevresel farkındalığı artırarak çevresel sürdürülebilirliğe destek olur. Kütüphaneleri herkes için ulaşılır kılmak, eğitim programları tasarlamak, teknolojiye yönelik eğitimler vermek, toplum sağlığını desteklemek ve güvenli ve güvenilir bir kaynak olmak toplumsal sürdürülebilirlik için en önemli kriterler olarak sayılabilir (Urban Libraries Council, 2011, s. 11).

Son olarak da Yıldırım ve Akkaya'nın (2020) çalışmalarına değinilebilir. Araştırmacılar bu çalışmada kütüphaneler ve sürdürülebilirlik açısından genel bir değerlendirmede bulunmaktadırlar. Çalışma sürdürülebilirlik kavramı ele alınarak başlamakta ve sürdürülebilirliğin ekonomik, sosyal ve çevresel boyutları değerlendirildikten sonra kurumsal sürdürülebilirliğin üzerinde durulmaktadır. Kurumsal sürdürülebilirlik çerçevesinde kütüphane bileşenleri ile ele aldıktan sonra, IFLA'nın raporuna atıf yapılarak sürdürülebilirlik adımlarında kütüphanelerin rolleri irdelenmektedir. Çalışma kütüphanelerin sürdürülebilirliğe olan katkıs1 açısından ülkemizde yapılmış en kapsayıcı çalışma olarak değerlendirilmektedir.

\section{Yöntem}

Kütüphanelerin sürdürülebilir kalkınmadaki rolünün IFLA tarafından daha net çizildiği söylenebilir. Bu yaklaşımla, kalkınma planlamasının ülke özelinde ülke ihtiyaçlarına yönelik olarak yapılmasının gerekli olduğu anlaşılmaktadır. Ülkemizde sürdürülebilir kalkınma adına Cumhurbaşkanlığı Strateji ve Bütçe Başkanlığı faaliyet yürütmektedir. İlgili birim tarafından amaçlara yönelik olarak bir web sitesi kurulmuş (http://www.surdurulebilirkalkinma.gov.tr/) olup,bu sayfada kalkınma hedeflerine yönelik ülkemizin hazırladı̆̆ı raporlar, amaçların tanımlanması, istatistiki göstergeler gibi birçok bilgiye yer verilmektedir. Doküman ve bilgilerin incelenmesi sonucunda ilgili hedefler doğrultusunda kütüphanelere yer ayırmadığg ve bir misyon yüklemediği görülmektedir. Önceki bölümlerde önemine değinildiği üzere; halk kütüphanelerinde yürütülen çalışmalar araştırılacaktır. Bu çalışmalardan kalkınma hedeflerine katkı sunanlar derlenecektir. Daha sonraki çalışmalarda kalkınma hedeflerine yönelik kütüphane politikaları oluşturulması için temel bir dayanak noktası hazırlanmıştır. Çalışmada sorun olarak görülen nokta, sürdürülebilir kalkınma hedeflerine yönelik çalışmalar planlanırken kütüphanelerin bu sürecin bir parçası olarak görülmemesidir. Bu gerçek ortaya konulduktan sonra, kütüphanelerin kalkınma hedeflerine etki edecek uygulamaları olduğu da ortaya koyulmuştur. Bunu yaparken aşağıdaki sorulara cevaplar aranmıştır:

- Kültür ve Turizm Bakanlığı'na bağlı kütüphanelerin faaliyetleri sürdürülebilir kalkınma hedefleri çerçevesinde midir?

- Bu faaliyetler sürdürülebilir kalkınma hedefleri gözetilerek mi yapılmıştır?

- Varoluşsal olarak kütüphaneler sürdürülebilir kalkınma için potansiyel ortaklar mıdır?

Araştırma sorularını dayanak alacak olan hipotez; “Kültür ve Turizm Bakanlığı'na bağlı kütüphaneler Sürdürülebilir Kalkınma Hedeflerini gerçekleştirmede doğaları gereği, farkında olmadan rol üstlenmektedirler" şeklinde oluşturulmuştur.

Çalışmada ortaya konan soruların yanıtları aranırken betimleme yöntemi kullanılmıştır. Betimleme yöntemi olayların, varlıkların, kurumların, grupların ve çeşitli alanların ne olduğunu açıklamaya çalışan bilimsel yöntemdir (Kaptan, 2000, s. 59). Veri toplama tekniği olarak içerik analizi tekniği kullanılmıştır. İçerik analizi yöntemi ile Kültür ve Turizm Bakanlığı'nın sitesinde yer alan 2006-2019 faaliyet raporları taranmıştır. Faaliyet raporlarından sürdürülebilir 
Sürdürülebilir Kalkınma Hedefleri Çerçevesinde Kültür ve Turizm Bakanlığı'na Bağlı Halk Kütüphanelerinin Faaliyetlerinin Değerlendirilmesi

Assessment of the Activities of Public Libraries Affiliated to the Ministry of Culture and Tourism within the Framework of Sustainable Development Goals

kalkınma hedeflerine uygun olan çalışmalar derlenmiştir. Söz konusu uygunluk değerlendirmesi, sürdürülebilir kalkınma hedeflerinden derlenmiş olan bir kontrol listesi aracılığı ile ölçülmeye çalışılmıştır. Liste, 16 madde altında alt başlıklara kadar indirgenerek hazırlanmış ve uzman görüşü de alındıktan sonra kullanılmıştır. 17. madde kalkınma hedeflerinin iç işlerliğine yönelik olduğu için, listede yer verilmemiştir. Liste kullanımı sonucunda elde edilen veriden yapılan çıkarımlarla alt başlıklara eklemeler yapılması zorunlu hale gelmiştir. Kontrol listesi içinde toplumsal kalkınma alanında dezavantajlı gruplara doğrudan değinen bir başlık olmaması ve kültürel gelişimin tam olarak işlenmemesi bu kararın alınmasında etkili olmuştur.

Sürdürülebilir kalkınma hedeflerine katkı sunan halk kütüphanesi örneklerini görmek adına, öncelikle sürdürülebilir kalkınma hedeflerinin tanımlandığı bir kontrol listesi hazırlanmıştır. Liste ilk başta kalkınma hedefleri bire bir uyarlanarak tasarlanmıştır. Bu kontrol listesi üzerine araştırma yapılırken, Kültür ve Turizm Bakanlığı faaliyet raporlarında yer alan bazı başlıklarında bu liste içinde yer alması gerektiği düşünülmüştür. Bunlardan ilki eşitsizliklerin azaltılması altında dezavantajlı grupların yer alması gerekliliğidir. Toplumsal gelişim için, toplumun her kesimine, hatta özellikle de toplumun geneli ile aynı imkânlara sahip olmayan gruplara yönelmek gerekmektedir. Kalkınma, engelli bireylere, yoksullara, azınlıklara eşit imkânlar tanıyarak mümkün olabilir (Gürsel ve Kolaşin, 2010, s. 1). Öte yandan sürdürülebilir kalkınma daha öncede söz edildiği gibi üç boyutta ele alınmaktadır. $\mathrm{Bu}$ alanlardan biriside sosyal boyuttur. Sosyal boyutu ise kültür ayağı olmaksızın düşünülemez. Sosyal ya da toplumsal olgular kültür ile örülmüşlerdir. Bu sebeple kültürün sürdürülebilir kalkınma kontrol listesi içinde değerlendirilmesi gerekmektedir.

Bu çıkarımlar sonucu dezavantajlı bireylere yönelik hizmetler eşitsizliklerin azaltılması başlığı altında, kültürel konular ise nitelikli eğitim altında kültürel gelişim olarak sınıflanmaktadır. Bu kararın sonucu olarak kontrol listesi son halini almıştır.

\section{Bulgular}

Yıllara göre belge tarama sonucu elde edilen faaliyetler aşağıdaki şekilde gruplandırılmıştır:

\section{6}

4) Nitelikli Eğitim

b) Kültürel faaliyetler ile bireysel gelişimi destekleme:

- 2394 adet kültürel etkinlik düzenlendi.

- Radyo tiyatroları desteklenmiştir.

8) İnsana Yakışır İş ve Ekonomik Büyüme

a) Teknolojik yeniliklere destek sunma:

- İnternete erişim projesi başlatılmıştır.

9) Sanayi, Yenilikçilik ve Altyapı

a) Ar-Ge'nin desteklenmesi:

- Hedef gruplara yönelik proje geliştirme eğitimleri verilmiştir.

\section{0) Eşitsizliklerin Azaltılması}

c) Dezavantajlı gruplara eşit firsatlar tanıma: 
- Beyazıt Devlet Kütüphanesinde sesli kitaplık oluşturma için 6 adet stüdyo ve brail baskı ünitesi kuruldu.

- Görme engellilere 500 CD ödünç verilmektedir.

- 20 pilot ilde evlere kitap hizmeti PTT ile anlaşma sağlanarak başlamıştır.

2007

4) Nitelikli Eğitim

b) Kültürel faaliyetler ile bireysel gelişimi destekleme:

- 4397 adet kültürel etkinlik düzenlendi.

8) İnsana Yakıșır İş ve Ekonomik Büyüme

a) Teknolojik yeniliklere destek sunma:

- 288 kütüphane için 300 bilgisayar ve 115 yazıcı alınmıştır.

9) Sanayi, Yenilikçilik ve Altyapı

a) Ar-Ge'nin desteklenmesi:

- Hizmet içi eğitimler ve seminerlerle yenilikçilik tetiklenmeye çalışılmıştır.

10) Eşitsizliklerin Azaltılması

c) Dezavantajlı gruplara eşit firsatlar tanıma:

- 13 konuşan kitaplık kuruldu.

- 20 pilot ilde 33 kişiye Eve Teslim Kitap Projesi kapsamında kitap sağlanmıştır.

\section{8}

4) Nitelikli Eğitim

b) Kültürel faaliyetler ile bireysel gelişimi destekleme:

- 4035 adet kültürel etkinlik düzenlendi

8) İnsana Yakışır İş ve Ekonomik Büyüme

a) Teknolojik yeniliklere destek sunma:

- 328 halk kütüphanesinde İnternet Erişimi Merkezleri kurulmuş olup, 5480 bilgisayarla ücretsiz olarak internet erişim hizmeti sağlanmıştır

- 288 kütüphaneye 350 bilgisayar ve yazıcı alınmıştır

- İl halk kütüphaneleri ve yazma eser kütüphaneleri web sayfaları için alt yapı oluşturulmuştur

- Yazma eserler dijitalleştirilmeye başlanmış ve internet ortamına atılması için hazırlıklar yapilmaktadir

9) Sanayi, Yenilikçilik ve Altyapı

a) Ar-Ge'nin desteklenmesi:

- Entegre E-Kütüphane projesi başlamıştır

\section{9}

4) Nitelikli Eğitim

b) Kültürel faaliyetler ile bireysel gelişimi destekleme:

- 4097 adet kültürel etkinlik düzenlendi

8) İnsana Yakışır İş ve Ekonomik Büyüme

a) Teknolojik yeniliklere destek sunma: 
Sürdürülebilir Kalkınma Hedefleri Çerçevesinde Kültür ve Turizm Bakanlı̆̆ı'na Bağlı Halk Kütüphanelerinin Faaliyetlerinin Değerlendirilmesi

Assessment of the Activities of Public Libraries Affiliated to the Ministry of Culture and Tourism within the Framework of Sustainable Development Goals

- 218 kütüphane için 383 bilgisayar temin edilmiştir.

- 605 kütüphanede kablosuz ağ kurulmuştur.

- 13 yazma eser ve 22 halk kütüphanesi web sayfaları yayınlanmıştır

- 42 e-kitap hizmete sunulmuştur

- Yazma eserlerin \%94'ü dijitalleştirilmiştir

9) Sanayi, Yenilikçilik ve Altyapı

a) Ar-Ge'nin desteklenmesi:

- Entegre E-Kütüphane projesi kapsamında 121 kurum kütüphanesine ait veriler sisteme aktarılmıştır

- Üniversitelerle iş birliğine gidilmiştir

10) Eşitsizliklerin Azaltılması

c) Dezavantajlı gruplara eşit firsatlar tanıma:

- 20 pilot ilde 93 kullanıcıya evlerinde 274 kitap sağlanmıştır

\section{0}

4) Nitelikli Eğitim

b) Kültürel faaliyetler ile bireysel gelişimi destekleme:

- 3707 adet kültürel etkinlik düzenlendi

8) İnsana Yakışır İş ve Ekonomik Büyüme

a) Teknolojik yeniliklere destek sunma:

- 505 kütüphanede kablosuz internet hizmeti verilmeye başlanmıştır

- 31 halk kütüphanesi web sayfası daha hizmete girmiştir

- Yazma eserlerin \%99’u sisteme aktarılmıştır

- 17 e-kitap daha hizmete sunulmuştur

9) Sanayi, Yenilikçilik ve Altyapı

a) Ar-Ge'nin desteklenmesi:

- Entegre E-Kütüphane projesi kapsamında toplukatalog.gov.tr kuruldu

2011

4) Nitelikli Eğitim

a) Herkes için kapsayıcı ve nitelikli eğitim:

- Türkiye okuma kültürü haritası çıkarılmıştır

b) Kültürel faaliyetler ile bireysel gelişimi destekleme:

- 3707 adet kültürel etkinlik düzenlendi

8) İnsana Yakışır İş ve Ekonomik Büyüme

a) Teknolojik yeniliklere destek sunma:

- 240 bilgisayar alınmıştır

- 50 il halk ve 83 ilçe halk kütüphanesinin web sayfaları yayınlanmıştır

9) Sanayi, Yenilikçilik ve Altyapı

a) Ar-Ge'nin desteklenmesi:

- TÜBESS çalışmaları başlamıştır 
- RFID teknolojisi kitaplarda kullanılmaya başlanmıştır

10) Eşitsizliklerin Azaltılması

c) Dezavantajlı gruplara eşit firsatlar tanıma:

- Görme engelli kullanıcılar için 85 kütüphaneye bilgisayar ve yazılım alınmıştır

- 176 kitap gönüllüler tarafından seslendirilmiştir

- Altı kayıt stüdyosunun yapımına başlanmıştır

- 20 pilot ilde evlerinde 82 kullanıcıya 196 kitap sağlanmıştır

2012

4) Nitelikli Eğitim

b) Kültürel faaliyetler ile bireysel gelişimi destekleme:

- 3248 adet kültürel etkinlik düzenlendi

8) İnsana Yakışır İş ve Ekonomik Büyüme

a) Teknolojik yeniliklere destek sunma:

- 225 bilgisayar internet erişimi için alınmıştır

9) Sanayi, Yenilikçilik ve Altyapı

a) Ar-Ge'nin desteklenmesi:

- TÜBESS faaliyetlerine başlamıştır

10) Eşitsizliklerin Azaltılması

c) Dezavantajlı gruplara eşit firsatlar tanıma:

- 473 kitap seslendirilmiştir

- 6 kayıt stüdyosunun yapımına tamamlanmıştır

\section{3}

4) Nitelikli Eğitim

a) Herkes için kapsayıcı ve nitelikli eğitim:

- 5 yeni gezici kütüphane alınmıştır

b) Kültürel faaliyetler ile bireysel gelişimi destekleme:

- $\quad 3276$ adet kültürel etkinlik düzenlendi

8) İnsana Yakışır İş ve Ekonomik Büyüme

a) Teknolojik yeniliklere destek sunma:

- 660 bilgisayar alınarak 25 yeni internet merkezi kurulmuştur

- Kütüphan-e Türkiye Projesi başlamıştır

2014

4) Nitelikli Eğitim

a) Herkes için kapsayıcı ve nitelikli eğitim:

- Beş gezici kütüphane alınmıştır

- Kütüphan-e Türkiye Projesi kapsamında personel ve kullanıcılara bilgi okur-yazarlığı eğitimleri verilmiştir.

b) Kültürel faaliyetler ile bireysel gelişimi destekleme:

- 2482 adet kültürel etkinlik düzenlendi

8) İnsana Yakışır İş ve Ekonomik Büyüme 
Sürdürülebilir Kalkınma Hedefleri Çerçevesinde Kültür ve Turizm Bakanlı̆̆ı'na Bağlı Halk Kütüphanelerinin Faaliyetlerinin Değerlendirilmesi

Assessment of the Activities of Public Libraries Affiliated to the Ministry of Culture and Tourism within the Framework of Sustainable Development Goals

a) Teknolojik yeniliklere destek sunma:

- 522 bilgisayar alındı ve 17 yeni bilgisayar merkezi kuruldu

b) Girişimciliği ve iş imkanlarını teşvik:

- 866 kişiye Kütüphan-e Türkiye Projesi kapsamında CV hazırlama, bilgisayar becerisi, web tasarımı, İngilizce gibi eğitimler verildi

\section{5}

\section{4) Nitelikli Eğitim}

a) Herkes için kapsayıcı ve nitelikli eğitim:

- 10 gezici kütüphane alınmıştır

b) Kültürel faaliyetler ile bireysel gelişimi destekleme:

- 2387 adet kültürel etkinlik düzenlendi

\section{8) İnsana Yakışır İş ve Ekonomik Büyüme}

a) Teknolojik yeniliklere destek sunma:

- 411 bilgisayar alınmış ve 27 yeni internet erişim merkezi kurulmuştur

b) Girişimciliği ve iş imkanlarını teşvik:

- Kütüphan-e Türkiye Projesi kapsamında 353eğitimde 3548 kişiye eğitim verilmiş, 3183 kişi mezun olmuştur

\section{6}

\section{4) Nitelikli Eğitim}

a) Herkes için kapsayıcı ve nitelikli eğitim:

- Beş gezici kütüphane alınmıştır

b) Kültürel faaliyetler ile bireysel gelişimi destekleme:

- 4024 adet kültürel etkinlik düzenlendi

\section{7}

\section{4) Nitelikli Eğitim}

a) Herkes için kapsayıcı ve nitelikli eğitim:

- Gezici kütüphane temin edilmiştir

b) Kültürel faaliyetler ile bireysel gelişimi destekleme:

- 5216 adet kültürel etkinlik düzenlendi

\section{8) İnsana Yakışır İş ve Ekonomik Büyüme}

a) Teknolojik yeniliklere destek sunma:

- 17000 e-kitap barındıran EBSCO veri tabanına abone olunmuştur

\section{9) Sanayi, Yenilikçilik ve Altyapı}

a) Ar-Ge'nin desteklenmesi:

- E-devlet ile entegre olunarak online işlemler e-devlet üzerine taşındı

- RFID kullanan kütüphane sayısı 21 e yükseldi

\section{8}

3) Sağlıklı Bireyler 
d)Herkese sağlık hizmeti ile güvenli ve erişilebilir ilaç imkânı sunmak:

- Sağlık Bakanlığı işbirliği ile Değişen Dünyada Gençler ve Ruh Sağlığı sempozyumları düzenlenmiştir

\section{4) Nitelikli Eğitim}

a) Herkes için kapsayıcı ve nitelikli eğitim:

- 10 gezici kütüphane alınmıştır

- Maker hareketi için çalışmalar başlamıştır

- İstanbul Gençlik Festivalinde maker atölyeleri düzenlenmiştir

- Ankara Hacı Ömer Tarman Anadolu Lisesinde bilgi okuryazarlığı eğitimi verilmiştir

- Adnan Ötüken Kütüphanesinde yaz programı düzenlenmiş ve çocuklara çeşitli eğitimler ve atölyeler verilmiştir

- 17 zekâ oyunundan 165 set alınıp kütüphanelere gönderilmiştir

b) Kültürel faaliyetler ile bireysel gelişimi destekleme:

- 6687 adet kültürel etkinlik düzenlendi

- 25 Türk Filmi kütüphanelerde gösterilmeye başlanmıştır

c) Varlık eşitsizliklerini ortadan kaldırma:

- 100 civarı çocuğun da yaşadığı Polatlı'da yer alan mevsimlik tarım işçilerinin kampında iki gün kütüphane şenliği düzenlenmiştir

8) İnsana Yakışır İş ve Ekonomik Büyüme

a) Teknolojik yeniliklere destek sunma:

- 19000 e-kitap barındıran EBSCO veri tabanına abone olunmuştur

9) Sanayi, Yenilikçilik ve Altyapı

a) Ar-Ge'nin desteklenmesi:

- E-devlet ile entegre olunarak online işlemler e-devlet üzerine taşındı

- RFID kullanan kütüphane sayısı 25'e yükseldi

\section{9}

\section{4) Nitelikli Eğitim}

a) Herkes için kapsayıcı ve nitelikli eğitim:

- Burdur'da bilgi okur-yazarlığı konferansı düzenlenmiştir

- Halk kütüphanelerinde bilgi okuryazarlığı çalıştayı Kırşehir'de düzenlenmiştir

- 28 çeşit zekâgeliştirici oyun 415 kütüphaneye dağıtıldı

- MEB ile eğitimde iş birliği protokolü imzalandı

b) Kültürel faaliyetler ile bireysel gelişimi destekleme:

- 11943 adet kültürel etkinlik düzenlendi

- 25 Türk ve dünya sinemasından filmler kütüphanelerde gösterime sokulmuştur ayrica hepsi ftp üzerinden erişime açılmıştır

- Kent arşivleri kurulmaya başlanmıştır

8) İnsana Yakışır İş ve Ekonomik Büyüme

a) Teknolojik yeniliklere destek sunma:

- 100 adet e-kitap yayınlanmıştır

9) Sanayi, Yenilikçilik ve Altyapı

a) Ar-Ge'nin desteklenmesi: 
Sürdürülebilir Kalkınma Hedefleri Çerçevesinde Kültür ve Turizm Bakanlı̆̆ı'na Bağlı Halk Kütüphanelerinin Faaliyetlerinin Değerlendirilmesi

Assessment of the Activities of Public Libraries Affiliated to the Ministry of Culture and Tourism within the Framework of Sustainable Development Goals

- E-devlet ile entegre olunarak online işlemler e-devlet üzerine taşındı

- RFID kullanan kütüphane sayısı 30'a yükseldi

\section{0) Eşitsizliklerin Azaltılması}

c) Dezavantajlı gruplara eşit firsatlar tanıma:

- Ceza infaz kurumlarına kitap sağlanması için Adalet Bakanlığı ile protokol imzalandı

Faaliyetler genel olarak ele alındığında, halk kütüphanelerinde2006-2019 arasında her yıl sürdürülebilir kalkınma hedeflerinden en az 2 ana hedefe uygun çalışma yürütüldüğü görülmektedir. Nitelikli eğitim hedefine yönelik her y1l istisnasız en az 2 faaliyet yürüten kütüphaneler için bu durum kütüphanelerin oluşumlarının doğal sonucudur denebilir. Türkiye'de okul kütüphanelerinin yetersiz kalışı ile halk kütüphaneleri sadece yaygın değil, ağırlıklı olarak örgün eğitime de destek sunmaktadır. Bunun sonucu olarak da raporlarda nitelikli eğitimi destekleyen faaliyetlerin olması kaçınılmazdır. Kütüphaneler eğitim alanında toplamda 36 ayrı tür faaliyet rapor etmişlerdir. Kütüphanelerin eğitim alanına verdikleri ağırlık buradan da net olarak anlaşılmaktadır. Eğitim alanından sonra ağırlık, 27 farklı faaliyet kaydı ile 8. alan olan İnsana Yakışır İş ve Ekonomik Büyüme alanıdır. Bu başlık altında yer alan teknolojik yeniliklere destek sunma, kütüphanelerin en sık faaliyet ürettiği ikinci alan olmuştur. $\mathrm{Bu}$ durumda genelde proje bazlı çalışmaların ve Bilgi Toplumu Stratejisi Eylem Planlarının sonucudur. Gelişen teknoloji çağında bilgi merkezlerinin de başka türlü hareket etmesinin beklenmemesi değerlendirilmektedir.

Tablo 1

Yıllara Göre Halk Kütüphanelerinin Sürdürülebilir Kalkınma Hedeflerine Yönelik Çalışmaları

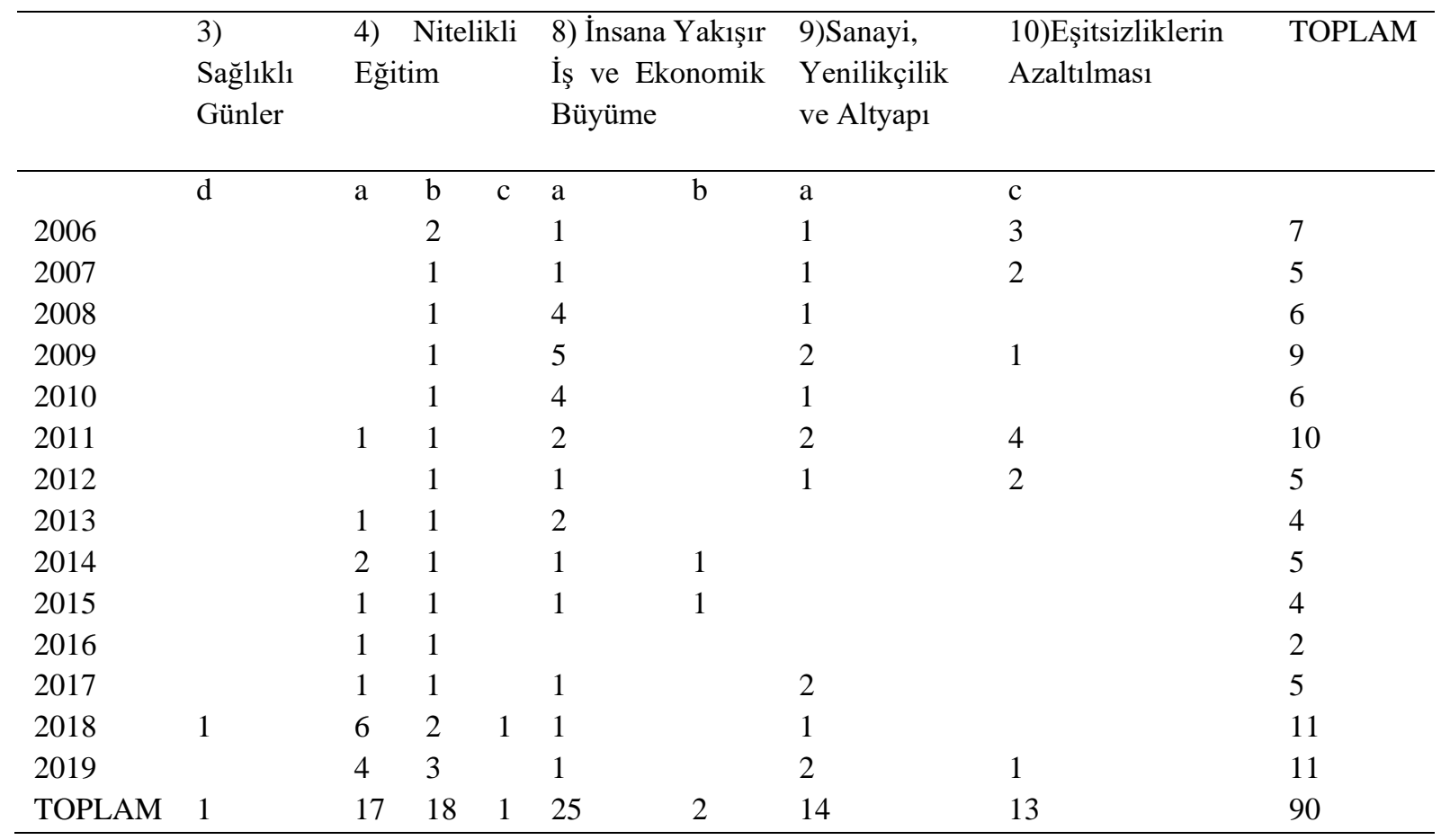


Faaliyetler genel olarakdeğerlendirildiğinde, 16 ana hedeften sadece 5 hedefe yönelik çalışmaların varlığından söz edilebilir. Bunlar; sağlıklı bireyler, nitelikli eğitim, insana yakışır iş ve ekonomik büyüme, sanayi, yenilikçilik ve altyapı ile eşitsizliklerin azaltılması başlıkları olarak sıralanabilir. En az yer verilen çalışma türleri ise sağlık ve dezavantajlı gruplara yönelik çalışmalar olmuştur. Toplamda sağlıklı bireylere yönelik bir faaliyet geliştirilmişken, dezavantajlı gruplara yönelik 13çalışma göze çarpmaktadır.

Yıllara göre baktığımızda ise en az çalışma 2016 yılında ve 2 tür faaliyetle gerçekleşmiştir. Genelde yıllar bazında 5 civarı faaliyet yürütülmüştür. 2018 ve 2019 yıllarında ise daha yoğun çalışmalar göze çarpmaktadır. 13 ve 11 faaliyet ile en çok çalışmanın yapıldığı yıllar bu iki yıl olarak gözükmektedir. Proje bazlı çalışmaların arttığ 2009 ve 2011 yılları da faaliyetlerin artış gösterdiği dönemler olmuştur.

Yukarıdaki bulgulara dayanarak “Kültür ve Turizm Bakanlığı'na bağlı halk kütüphanelerinin faaliyetleri sürdürülebilir kalkınma hedefleri çerçevesinde midir?” sorusuna olumlu yanıt verebiliriz. Her ne kadar hedeflerin tamamına yönelik faaliyetler yürütülmemişse de 5 ana hedef altında 8 alt hedefe yönelik birçok faaliyet gerçekleştirilmiştir. 14 yılda hedeflere yönelik 90 faaliyet ile halk kütüphanelerinin bu konuda varlıkları gereği bir misyonu olduğunun ifade edilmesi mümkündür. Halk kütüphanelerinin eğitim ve teknoloji konusunda sürdürülebilir kalkınma hedeflerine yönelik olumlu katkılar sunduğu da ifade edilebilir. Diğer araştırma soruları "Bu faaliyetler sürdürülebilir kalkınma hedefleri gözetilerek mi yapılmıştır?" ve "Varoluşsal olarak kütüphaneler sürdürülebilir kalkınma için potansiyel ortaklar mıdır?" ise şu şekilde değerlendirilmiştir ve cevaplanmaya çalışılmıştır: Bakanlık sürdürülebilir kalkınma hedeflerine yönelik maalesef ki bir vizyon belirlememiştir. Faaliyetlerini yürütürken de dayanak sağladı̆̆ı tek kurum dışı politika Bilgi Toplumu Stratejisi Eylem Planları olmuştur. Proje temelli çalışmalar dışında başka bir faaliyet planı bulunmayan halk kütüphaneleri bu eylemleri görevleri olduğu için yapmışlardır. Halk Kütüphaneleri Yönetmeliği’nde halk kütüphanelerinin işlevleri aşağıdaki şekilde tanımlanır:

a) Halkın bilgi edinme gereksinimini karşılar.

b) Bireysel ve yaşam boyu öğrenme çabalarını destekler.

c) Başta çocuklar olmak üzere, bölge halkında okuma kültürü ve kütüphane kullanma alışkanlığ 1 yaratır ve güçlendirir.

ç) Toplumun bilgi okur-yazarlığı becerisi kazanmasını ve geliştirmesini sağlar.

d) Her düzeyde örgün ve yaygın eğitimi destekler.

e) Çocuk ve gençlerin zihinsel yaratıcılıklarını geliştirmelerini destekler ve bu yönde firsatlar sağlar.

f) Öncelikle bulunduğu bölge olmak üzere, toplumun kültürel ve sosyo-ekonomik kalkınmasına destek sağlar.

g) Toplumda kültürel mirasa, sanata ve bilime karşı duyarlılık oluşturur ve bu bilincin geliştirilmesini sağlar.

g) Somut olmayan yerel kültür mirasının toplanması, düzenlenmesi, korunmas1, kullandırılması ve geleceğe aktarılmasına katkı sağlar ve sözlü geleneği destekler.

h) Kültürler arası diyalogu geliştirmeye katkı sağlar (Halk Kütüphaneleri Yönetmeliği, 2012). 
Sürdürülebilir Kalkınma Hedefleri Çerçevesinde Kültür ve Turizm Bakanlığı'na Bağlı Halk Kütüphanelerinin Faaliyetlerinin Değerlendirilmesi

Assessment of the Activities of Public Libraries Affiliated to the Ministry of Culture and Tourism within the Framework of Sustainable Development Goals

Yönetmelikte yer alan ilk beş işlev, sürdürülebilir kalkınma hedeflerinde yer alan eğitim maddesini destekler niteliktedir. Yönetmelikte yer alan (f) ve (g) maddeleri; Sürdürülebilir Kalkınma Hedefleri'nden insana yaraşır iş ve ekonomik büyüme hedefine, yoksulluğa son hedefine, açlığa son hedefine yönelik kütüphanelerin rol üstlendiğini göstermektedir. Öte yandan $(\breve{\mathrm{g}})$ ve $(\mathrm{h})$ maddeleri ile de barış adalet ve güçlü kurumlar hedefi ile eşitsizliklerin azaltılması hedefine dair kütüphanelerin sorumlulukları olduğu görülmektedir. Yani buradan hareketle kütüphanelerin doğal olarak sürdürülebilir kalkınmayı destekler kuruluşlar olduğu ifade edilebilir. Bilgi ve eğitim alanının öncü kuruluşları olmaları sebebiyle kütüphaneler bu misyonu doğuştan edinmektedirler.

Araştırma sorularına alınan cevaplar 1şığında “Kültür ve Turizm Bakanlığı'na bağlı halk kütüphaneleri sürdürülebilir kalkınma hedeflerini gerçekleştirmede rol üstlenmektedir" çalışmanın hipotezinin doğrulanmış olduğu ifade edilebilir.

\section{Sonuç ve Öneriler}

Çalışmada sürdürülebilir kalkınma kavramı ele alınmış ve kütüphane ekseninde değerlendirilmiştir. Sürdürülebilir kalkınma BM çerçevesinde tanımladıktan sonra, IFLA'nın bu konudaki yaklaşımı ele alınmış ve ülkemiz açısından yapılan değerlendirmelere odaklanılmıştır. Özellikle beş yıllık kalkınma planları uyarınca kütüphanelerde yürütülen çalışmalara dikkat çekilen bölümde, kütüphanenin kalkınmadaki rolü açıklanmaya çalışılmıştır. UNESCO'nun çalışmalarının da değerlendirildiği ilgili bölümde, Türkiye'deki durumun sürekli eksik ilerlediği, halk kütüphanesi hizmetinin tabana istenildiği gibi yayılamadığı görülmüştür. Kaliforniya Üniversitesi, Kent Kütüphaneleri Konseyi gibi öncü kurumların değerlendirilmeleri de dikkate alındığında, gerek IFLA'nın sürdürülebilir kalkınmada kütüphanelere biçtiği rolün, gerekse de Kent Kütüphaneleri Konseyi'nin sürdürülebilir kütüphaneler için ortaya attığ modelin çok da farklı olmadığı anlaşılmıştır. Genel ve toplayıcı bir çalışma olarak Yıldırım ve Akkaya'nın çalışmasına da değinilen literatür kısmından sonra bulgulara geçilmiştir.

Bulgular kısmında Kültür ve Turizm Bakanlığı'nın faaliyet raporları (2006-2019) değerlendirilmiştir. Değerlendirmede, bu çalışma için geliştirilen Sürdürülebilir Kalkınma Hedefleri Kontrol Listesi kullanılmıştır. Raporlar içinde yer alan hedeflere uygun faaliyetler içerik analizi yöntemi ile tespit edilmiş ve sınıflanmıştır. Sürdürülebilirlik kavramı ile kütüphaneler için ne anlama geldiğinin çok da farkında olmadan bu hedeflere yönelik çalışmalar yürütülmüştür. $\mathrm{Bu}$ çalışma sonucunda da halk kütüphanelerinin Sürdürülebilir Kalkınma Hedeflerine destek oldukları gözlenmiştir. Halk kütüphanelerinin sürdürülebilir kalkınma hedeflerinin doğal destekçisi olması bu amaçlara ulaşılırken halk kütüphanelerinin de politikaların bir parçası olması gerektiğini göstermektedir.

Bu sonuçlar ışığında aşağıdaki öneriler sunulabilir;

- Halk kütüphaneleri toplumsal gelişmenin tam içinde yer aldıkları için sürdürülebilir kalkınma hedeflerinin gerçekleştirilmesinde önemli roller almalıdırlar.

- Varoluşları gereği bile 13 yıldır beş ana hedefe katkı sunan halk kütüphaneleri diğer hedefler içinde faaliyetler yürütmelidirler. 
- $\mathrm{Bu}$ faaliyetlerin Cumhurbaşkanlığı Strateji Geliştirme ve Bütçe Başkanlığı ile koordineli yapılması önemlidir.

- TÜİK göstergelerinde Sürdürülebilir Kalkınma Hedefleri altında kütüphane istatistiklerine de yer verilmelidir.

- Bakanlık, halk kütüphanelerinin birer toplum merkezi olmasını sağlamalıdır.

- IFLA'nın çizdiği yol haritası Kütüphaneler ve Yayımlar Genel Müdürlüğü tarafından benimsenmeli ve buna uygun adımlar atılmalıdır.

- IFLA'nın 17 hedef için verdiği örnekler incelenmeli ve Türkiye'de bu listeye kendi örneklerini eklemelidir.

○ 17 hedef kapsamında kütüphaneler için politikalar geliştirilmelidir.

- $\mathrm{Bu}$ politikaların etkin olabilmesi için hizmet içi eğitimler düzenlenmeli ve kütüphanecilerin farkındalıkları artırılmalıdır.

- Halk kütüphanesi hizmeti nüfus ve kullanım verileri baz alınarak tabana yayılmalıdır.

- IFLA yol haritası meslek derneklerimizce de benimsenerek uygulanmalıdır.

\section{Kaynakça}

Birleşmiş Milletler. (2020). Sürdürülebilir kalkınma amaçları. UNDP Türkiye. Erişim adresi https://www.tr.undp.org/content/turkey/tr/home/sustainable-development-goals.html

California University. (2020). What is sustainability? UCLA sustainability. Erişim adresi https://www.sustain.ucla.edu/about-us/what-is-sustainability/

Çapar, B. (1987). Kütüphane hizmetlerinin planlanmasında UNESCO’nun rolü ve Türkiye. Türk Kütüphaneciliği, 1(4), 162-174-174.

[Gürsel, S. ve Kolaşin, G. U.]. (2010). İstihdamda dezavantajlı grupların işgücüne katılımını artırmak. BETAM/ Bahçeşehir Üniversitesi Ekonomik ve Toplumsal Araştırmalar Merkezi. Erişim adresi https://docplayer.biz.tr/11575964-Istihdamda-dezavantajli-gruplarin-isgucune-katiliminiartirmak.html

Holt, İ. (2003). Avrupa Birliği ve kütüphaneler [Thesis, Istanbul University (Turkey)]. Erişim adresi http://eprints.rclis.org/5451/

IFLA. (2016). Kütüphaneler ve BM 2030 Gündemi’nin uygulanması (Herkes için Kütüphane Program Ofisi, Çev.). Türk Kütüphaneciliği, 30(2), 319-337.

Kaptan, S. (2000). Bilimsel araştırma ve istatistik teknikleri (11. bs). Ankara: Bilim Yayınevi.

Karadeniz, Ş. ve Yılmaz, B. (2016). Türkiye'nin 2015-2018 Bilgi Toplumu Stratejisi ve Eylem Planı'nda kütüphane kurumuna yaklaşım. Türk Kütüphaneciliği, 30(1), 59-83-83.

Kılıç, S. (2013). Sürdürülebilir kalkınma anlayışının ekonomik boyutuna ekolojik bir yaklaşım. İstanbul Üniversitesi Siyasal Bilgiler Fakültesi Dergisi, 47, 201-226.

Halk Kütüphaneleri Yönetmeliği, Pub. L. No. 28170 (2012). Erişim adresi https://teftis.ktb.gov.tr/TR14656/halk-kutuphaneleri-yonetmeligi.html

Mohrhardt, F. ve Carlos, V. P. (1975). National planning for library and information services. Voigt, M. J. (Ed.). Advances in Librarianship, 5, 61-106. New York: Academic Press.

Özdemirci, F. (1987). Beş yıllık kalkınma planlarında halk kütüphanelerimiz. Türk Kütüphaneciliği, l(4), 196-208-208.

Parker, J. S. (1985). UNESCO and library development planning. London (UK): The Library Association. 
Sürdürülebilir Kalkınma Hedefleri Çerçevesinde Kültür ve Turizm Bakanlı̆̆ı'na Bağlı Halk Kütüphanelerinin Faaliyetlerinin Değerlendirilmesi

Assessment of the Activities of Public Libraries Affiliated to the Ministry of Culture and Tourism within the Framework of Sustainable Development Goals

UNESCO Türkiye Millî Komisyonu. (1974). UNESCO Türkiye Millî Komisyonu Yönetim Kurulu Raporu. Ankara: [UNESCO Türkiye Milli Komisyonu?].

Urban Libraries Council. (2011). Partners for the future: Public libraries and local governments creating sustainable communities. Urban Libraries Council. Erişim adresi https://icma.org/sites/default/files/303033_Sustainability_FullReport_CopyRight_2010\%20\% 282\%29.pdf

Yıldırım, Z. ve Akkaya, M. A. (2020). Kütüphaneler ve sürdürülebilirlik ilişkisi: Genel bir değerlendirme. Çankırı Karatekin Üniversitesi Edebiyat Fakültesi Dergisi, 8(1), 18-46.

Ek

\section{Kontrol Listesi}

\section{Sürdürülebilir Kalkınma Kontrol Listesi}

1) Yoksulluğa Son

a) En zor durumdakilerin hedeflenmesi

b) Temel kaynaklara erişimin artırılması

c) Çatışmalardan ve İklim değişikliğinden etkilenen toplumlara destek verilmesi

\section{2) Açlığa Son}

a) İnsanlara ve başta çocuklara yeterli besin sağlama

b) Küçük çiftçilerin ve sürdürülebilir tarımın desteklenmesi

c) Tarımda verimliliği artırmak için alt yapı ve destek uygulamalarının desteklenmesi

\section{3) Sağlıklı Bireyler}

a) Başta çocuk ölümlerinin önüne geçmek için aşı, tedavi, üreme sağlı̆̆ gibi konularda çalışmalar yapma

b) AIDS, verem, sitma ve diğer bulaşıcı hastalıklarla mücadele

c) Aşı araştırmalarını desteklemek

d) Herkese sağlık hizmeti ile güvenli ve erişilebilir ilaç imkanı sunmak

\section{4) Nitelikli Eğitim}
a) Herkes için kapsayıcı ve nitelikli eğitim
b) Uygun maliyetli mesleki eğitim
c) Varlık eşitsizliklerini ortadan kaldırma
d) Nitelikli yükseköğrenim firsatı sunma
e) Kültürel faaliyetler ile bireysel gelişimi destekleme

\section{5) Toplumsal Cinsiyet Eşitliği}

a) Kadınları her alanda eşit hakları için destek sunma

b) Kadın liderleri teşvik etme

\section{6) Temiz Su ve Sıhhi Koşullar}

a) Herkesin temiz içme suyuna erişmesi

b) Ormanlar, dağlar, nehirleri bu anlamda koruma

c) Aritma teknolojilerini destekleme

7) Erişilebilir ve Temiz Enerji

a) Güneş, rüzgâr, dalga ve termal gibi enerji kaynaklarına yatırım 
8) İnsana Yakışır İş ve Ekonomik Büyüme
a) Teknolojik yeniliklere destek sunma
b) Girişimciliği ve iş imkanlarını teşvik

9) Sanayi, Yenilikçilik ve Altyapı

a) Ar-Ge'nin desteklenmesi

10) Eşitsizliklerin Azaltılması

a) Gelir eşitsizliğinin azaltılması

b) İnsanlara göçlerinde destek olma

c) Dezavantajlı gruplara eşit firsatlar tanıma

11) Sürdürülebilir Şehir ve Yaşam Alanları
a) Yeşil alanlar yaratma
b) Gecekonduları dönüştürme

12) Sorumlu Tüketim ve Üretim
a) Daha verimli üretimi destekleme
b) Gıda atığının azaltılmasına yardım

\section{3) İklim Eylemi}

a) Küresel 1sınma ile mücadele

14) Sudaki Yaşam

a) Denizi ve kıyı ekosistemlerini koruma

\section{5) Karasal Yaşam}
a) Karasal ekosistemi korumaya destek
b) Ormanlaşmaya destek
c) Doğal yaşamı destekleme

16) Barış, Adalet ve Güçlü Kurumlar
a) Şiddeti azaltmaya ve güvenliği artırmaya destek
b) Hukukun üstünlüğüne katk1 